The University of Southern Mississippi

The Aquila Digital Community

Faculty Publications

$1-1-2019$

\title{
Antecedents and Consequences of Self-Congruity: Replication and Extension
}

\author{
Eugene Cheng-Xi Aw \\ University Putra Malaysia \\ Leisa Reinecke Flynn \\ University of Southern Mississippi, Leisa.Flynn@usm.edu \\ Han Xi Chong \\ University Putra Malaysia
}

Follow this and additional works at: https://aquila.usm.edu/fac_pubs

Part of the Marketing Commons

\section{Recommended Citation}

Aw, E. C., Flynn, L. R., Chong, H. X. (2019). Antecedents and Consequences of Self-Congruity: Replication and Extension. Journal of Consumer Marketing, 36(1), 102-112.

Available at: https://aquila.usm.edu/fac_pubs/15912

This Article is brought to you for free and open access by The Aquila Digital Community. It has been accepted for inclusion in Faculty Publications by an authorized administrator of The Aquila Digital Community. For more information, please contact Joshua.Cromwell@usm.edu. 


\title{
Antecedents and Consequences of Self-Congruity: Replication and Extension
}

\author{
Eugene Cheng-Xi Aw \\ Department of Management and Marketing, University \\ Putra Malaysia, Serdang, Malaysia
}

\begin{abstract}
Leisa Reinecke Flynn
Department of Marketing and Merchandising, College of Business, University of Southern Mississippi, Hattiesburg, USA
\end{abstract}

Han Xi Chong

Department of Resource Management and Consumer Studies, University Putra Malaysia, Serdang, Malaysia 


\begin{abstract}
Purpose

The purpose of this study is to propose and empirically test a framework encompassing self-congruity with its antecedents and consequences. This study also aims to test the mediating role of perceived value and its dimensions.

Design/methodology/approach
\end{abstract}

A questionnaire-based survey was conducted using a purposive sampling technique. Three hundred and ten useable responses were collected and data were analyzed using Partial Least Square Structural Equation Modeling.

\title{
Findings
}

A majority of hypotheses were supported. Avoidance of similarity and status consumption positively influenced self-congruity, replicating an earlier study. Selfcongruity positively influenced overall perceived value and its dimensions, as well as revisit intention. Overall perceived value and its dimensions positively influenced revisit intention. Lastly, overall perceived value and its dimensions were found to have a mediating effect on the relationship between self-congruity and revisit intention. Originality/Value

This study provides empirical evidence for the antecedents and consequences of selfcongruity with a service, and expands understanding of the mediating role of overall perceived value and its dimensions in predicting intention. 


\section{Introduction}

It is well-documented in the marketing literature that consumers are inclined to be more attached to products, services, and brands that express important aspects of themselves, such as self-identity, value, and goals (Aguirre-Rodriguex et al., 2012). People consume not only for functional benefits but also for the symbolic meanings behind brands (McCracken, 1986), and they are likely to purchase and use branded products that represent the meanings relevant to themselves (Fournier, 1998). These products possess characteristics that are said to be self-congruent. This marketing research has been valuable for product and retail store managers who strive to create an image of their offerings appealing to a desired market segment. Humanizing a brand and making it relatable to a consumer's self-concept creates positive brand attitude and can motivate purchase behavior (MacInnis and Folkes, 2017).

With the power of self-congruity as a driver, Roy and Rabbanee (2015) developed a model to stretch understanding of the construct to more of its antecedents and consequences. In this paper, we build on Roy and Rabbanee's (2015) model and apply it to a luxury food and beverage service category, specifically, branded coffee cafés in Malaysia. Our contribution is built on our addition of both perceived value and its specific dimensions to the model and testing these as mediators between self-congruity and revisit intention. This new model also goes further in that it contains revisit intention as its final outcome thus offering concrete evidence of the power of self-congruity to drive consumer behavior. 
Coffee is a habit-forming drink for many Malaysians and those coffee consumers are now becoming more sophisticated in demanding quality coffee (Goi, 2013). Branded coffee cafés are emerging as one of the fastest growing business segments in the food and beverage industry (Agriculture and Agri-Food Canada, 2014). In Malaysia, the coffee drinking culture has been growing and is now attracting investment from a number of coffee retailers (Goi et al., 2014). This is reflected in the rapid expansion of retail coffee franchises, such as Starbucks, Coffee Bean \& Tea Leaf, and San Francisco Coffee. Taking Starbucks Malaysia as an example, with more than 215 stores nationwide, it has achieved revenues of RM554.36 million for financial year ended 2016, and the growth is expected to continue (Berjaya Food Berhad, 2016).

Branded coffee cafés offer more than food and beverage; the extra that they provide is an ambience that makes people feel comfortable. Correspondingly, current literature on coffee cafés is centered on service quality, product quality, and atmosphere quality as capturing customer perceived value and driving revisit intention (Ting and Thurasamy, 2016; Lin and Yun, 2016; Susanty and Kenny, 2015). As asserted by Susanty and Kenny (2015), marketers in the coffee-shop business should have a thorough understanding of consumer behavior to develop marketing programs that align with customers' desires, thoughts, feelings, images, beliefs, and perceptions. The attributes and factors detailed in current literature are insufficient to accurately capture customer value and revisit intention. A more in-depth investigation into consumers' internal interactions with branded coffee cafés is needed to provide a more comprehensive view. 
Due to the intense competition among branded coffee cafés, and also between branded coffee cafés and conventional coffee shops, understanding consumers' perceptions and revisit intentions is crucial (Ting and Thurasamy, 2016). Some of the main themes in modern marketing are related to how well a product reaches or reflects the self. Creating superior value is essential for firms and it has become a growing managerial concern (Mencarelli and Riviere, 2015). Value can be enhanced by the self-brand congruence, and the belief that a brand provides value has been found to be the antecedent of consumer behavioral intention (Sweeny and Soutar, 2001; Parasuraman and Grewal, 2000; Zeithaml, 1988). Subsequently, customer retention has long been viewed as a powerful ingredient for business survival in a competitive environment (Clark, 1997). Retention is also important for long term sustainability because acquiring new customers may incur more cost than retaining an existing one (Fornell and Wernerfelt, 1987). Self-congruity has been shown to be related to consumer attitude, behavior and intention (AguirreRodrigues et al., 2012). Despite the importance and prospect of the industry, little study has been done to probe customer perception and revisit intention towards branded coffee cafés in the context of developing markets (Ting and Thurasamy, 2016).

Branded coffee cafés are examples of consumer service organizations that can be luxury branded and thus appeal to consumers' ideal or real selves. If marketers are able to understand the self-connection between individuals and their branded coffee cafés, they will be empowered in designing a more effective and specific marketing strategy. Unfortunately, very little research has been done on psychological drivers of attaining 
self-congruity (Roy and Rabbanee, 2015), and how self-congruity leads to revisit intention in the context of branded coffee cafés business remains largely unknown.

This study uses branded coffee cafés as an example of luxury consumption within a Generation Y cohort to extend the model proposed by Roy and Rabbanee (2015). The researchers integrate the drivers and consequences of self-congruity. The plan is to develop theoretical and practical insight into revisit intention by understanding more about the antecedents and outcomes of customers' self-congruity. Previous research on self-congruity focused more on pre-purchase perceptions and decisions (Hosany and Martin, 2012). As branded coffee cafés business involves service and experiential attributes, we investigate through a post-consumption lens.

The rest of the paper is structured as follows: the next section provides literature review and hypothesis development. Then, the research methodology is discussed, followed by data analysis and results. Subsequently, discussion and implications are presented.

Finally, limitations of the study are presented, along with suggestions for future research.

\section{Literature review and hypotheses development}

Self-congruity

Self-congruity refers to the subjective experience resulting from the interaction between an individual's self-concept and the product-user image (Sirgy et al., 1997). It is used in the same way as terms, such as "self-image congruence", "self-congruence," and "image congruence" in the consumer behavior literature. Self-concept refers to an 
individual's perception of "self" in terms of his or her characteristics, such as social class and age (Sirgy, 1982). There are four types of self-concept, namely actual-self (me as I am), ideal-self (how a person would like to see themself), social-self (how others see the person) and ideal-social self (how a person would like to be perceived by others). Selfcongruity can be achieved through the interaction between self-concept dimensions and the product-user image (Hosany and Martin, 2012; Sirgy et al., 2000). Product-user image is a function of value-expressive or symbolic features, which reflects a user's impression of products or services as described with various adjectives, such as friendly, modern, classy, young, and so on (MacInnis and Jaworski, 1989).

Self-congruity influences an individual's purchase motivation through satisfying selfconsistency motives, self-esteem motives, social consistency, and social approval needs (Aguirre-Rodriguez et al., 2012; Sirgy, 1985). These motivations and needs prompt individuals to purchase and use products that they consider as contributing to their understanding of themselves as well as the image they want to present to others (Kressman et al., 2006).

Self-congruity is important in explaining consumer behavior (Roy and Rabbanee, 2015; Sirgy et al., 1997). For instance, according to self-congruity theory, high levels of congruence between an individual's self-image and a perceived product image will increase the likelihood of both purchase (Sirgy et al., 1997; Sirgy, 1982) and brand loyalty (Kang et al., 2015). "Based on a branding strategy that incorporates the target customers' self-concept and distinct, congruent brand personality, a firm can induce 
feelings of brand attachment and commitment from its customers, and thus, build a longterm relationship with them" (Kim et al., 2005). More specifically, consumers consider symbolic meaning as well as utilitarian function when evaluating products. The congruity between self-image and product-user image leads to favorable evaluation of both, as products are a means for self-expression (Graeff, 1996). As such, self-congruity has been discovered to positively influence consumer behavior outcomes, such as attitude, satisfaction, purchase intention, and loyalty across different contexts (Kang et al., 2015; Aguirre-Rodriguez et al., 2012; He and Mukherje, 2007).

Based on the reasoning, it is hypothesized that:

H1: Self-congruity positively influences revisit intention.

\section{Perceived value}

Perceived value has been recognized as the basis for all marketing activity (Holbrook, 1994) and as a key source of competitive advantage (Eggert and Ulaga, 2002). Perceived value is referred to consumers' perception of an activity's subjective worth or objective consideration regarding the ratio of costs to benefits of consumption (Babin et al., 1994). It has emerged as a driving factor for behavioral outcomes in the marketplace (Hwang and Kandampully 2015). In this study we use the PERVAL model developed by Sweeney and Soutar (2001) which conceptualizes perceived value as having four dimensions, namely functional, monetary, social, and emotional values. According to Sweeney and Soutar (2001), functional value refers to the practical benefits provided by branded coffee cafés through their expected performance and perceived quality. Monetary value refers to the utility branded coffee cafés provide in proportion to 
the overall costs. Emotional value is the psychological utility branded coffee cafés create through feelings or affective states. Lastly, social value is the utility conveyed by branded coffee cafés through enhancing an individual's perceived social standing.

In general, perceived value can be seen as the subjective evaluation of products as influenced by the individual's qualities and attributes which originate from the self ( $\mathrm{He}$ and Mukherjee, 2007). Favorable self and social image exert influence on affective and cognitive judgments. The biasing effect of self-congruity on a customer's perception of functional attributes has been reported in several studies (Lu and Xu, 2015; Sirgy et al., 1991). Hence, the value offered by a branded retailer is likely to be evaluated favorably by customers if purchase and use is self-congruent.

However, the dimensionality issue of perceived value warrants future study. For instance, Ha and Im (2012) proposed the association between self-congruity and both hedonic and utilitarian value in a shopping context. They used completion of a shopping task as their sole measure of utilitarian value. This is a drawback of their study and potentially explains their finding of an insignificant relationship between self-congruence and utilitarian value. Ideally, specific dimensions, such as functional and monetary value should be taken into consideration to reflect utilitarian value in a better way. Furthermore, although previous studies evidenced the effect of self-congruity on perceived value (Kim and Thapa, 2017; He and Mukherjee, 2007), they treated perceived value as a unidimensional construct which offers less practical value. 
This current study sheds some light on the role of multidimensional value perception in relation to self-congruity. As a subjective judgment, perceived value is asserted to be possibly influenced by image-related perception, such as self-congruity (He and Mukherjee, 2007). In particular, it has been indicated that positive self-congruity can inflate the evaluation of utilitarian attributes of a product, such as functional and monetary values (Shamah et al., 2017; Sirgy, 1991). Besides, as manifested by Hosany and Martin (2012), self-congruity is associated with psychological experience. Arguably, it can be assumed that positive self-congruity enhances the feeling and emotional experience gained from patronage of branded coffee cafés. Social value can be explained from the perspective of how use of the product can confer social recognition (Sweeney and Soutar, 2001). Branded coffee cafés are different from normal coffee cafés because they not only serve as a place for food and beverage, but more so as a place to socialize. As people tend to create and portray their ideal selves in the socialization process, possibly for the purposes of achievement and status, branded coffee cafés have become the means to convey social value.

Consumers establish attachment to a service when the service delivers value that meets their needs (Sheth et al., 1991). So long as these needs are met there remains motivation for a continuous relationship with the provider. Past studies in the food and beverage sector have found positive value perception as a significant predictor of revisit intention (Ting and Thurasamy, 2016; Nadiri and Gunay, 2013). In addition, intention is commonly studied as a mediator to understand and predict how perception might influence subsequent behavior. Hence, if consumers of branded coffee cafés perceive 
high value from their service experience, they are more likely to revisit. This study proposes to test the notion that self-congruity impacts revisit intention both directly and indirectly through the perception of value in a more fine-grained way by looking into the role of specific value dimensions.

Thus, the following hypotheses are formulated:

H2: Self-congruity positively influences overall perceived value.

H3: Self-congruity positively influences functional, emotional, monetary, and social values.

H4: Overall perceived value positively influences revisit intention.

H5: Functional, emotional, monetary, and social values positively influence revisit intention.

H6: Overall perceived value mediates the relationship between self-congruity and revisit intention.

H7: Functional, emotional, monetary, and social values mediate the relationship between self-congruity and revisit intention.

\section{Avoidance of similarity}

While we usually think of humans as trying to fit into social circles, this tendency can move in the opposite direction and take the form of avoiding being too similar to others, especially when one wants to be different and unique. Social interactions sometimes encourage striving to be unique (Roy and Rabbanee, 2015). Need for uniqueness is considered as an individual difference variable where consumers have a greater or lesser need to stand out or be non-conforming (Tian et al., 2001). These 
consumers may achieve the avoidance of similarity or non-conformity by acquisition of consumer goods that develop and enhance their personal and social identity (Tian et al., 2001; Simonson and Nowlis, 2000).

Tian et al. (2001) conceptualized avoidance of similarity as, "loss of interest in, or discontinued use of, possessions that become commonplace in order to move away from the norm and reestablish one's differentness". This is the tendency to reject objects or behaviors that consumers feel make them look like they are trying to emulate others. Thus, for these consumers who want to express themselves through avoidance of similarity, there is an inverse relationship between what they see as the norm and how they would like to be seen. For them, the choice of a brand that is not perceived to be common would be more desired and provide self-congruity. Consumers who are higher in avoidance of similarity want to stand out as different. This is in line with Veblen's (1899) argument that people consume conspicuously to detach themselves from others. This study presumes that consumers of branded coffee cafés are driven by avoidance of similarity with others, in this case, those who visit local and non-internationally branded coffee cafés. Thus, the consumption of luxury coffee brands like Starbucks, demonstrates a consumer's specialness and adds to social distinctiveness (Sirgy, 1982).

Consumers high in avoidance of similarity are clearly displaying an aspect of their selfconcept as one who stands out from the crowd. Arbore et al. (2014) showed that need for uniqueness, of which avoidance of similarity is a factor, was related to self-concept. In their model, need for uniqueness was a second order factor determined by symbolic 
drivers of personal self which in turn was strongly related to self-identity. In short, consumers of branded coffee cafés may achieve better self-congruity by visiting branded coffee cafés as this behavior demonstrates their distinctiveness.

The following hypothesis is therefore derived:

H8: Avoidance of similarity positively influences self-congruity.

\section{Status consumption}

Status consumption is defined as, "the motivational process by which individuals strive to improve their social standing through the conspicuous consumption of consumer products that confer and symbolize status for both the individual and surrounding significant others.," (Eastman et al.,1999). This definition comes from an understanding that consumers use products and services in a way that shows their desired self-image to others. If an individual desires to convey his status within and outside of his social group, he or she can do so by consuming and displaying what the elite members consume and display. This idea has its written origins with the work of Veblen (1899). The human tendency to display for status may vary by culture. According to Ahuvia et al. (1995), in an Asian context where group identity is important, status consumption may not solely be a reflection of materialistic personal values but due to subjective norms and maintenance of group status. Heaney et al. (2005) asserted that it is important to investigate status consumption in Asian settings where such attitudes may not only be different from those found in Western settings but also show variance between Asian countries. 
Status consumption is a manifestation of self-congruity with products or services that connote social rank. One way to look at the relationship between status consumption and self-congruity is found in identity theory. Identity theory shows, "how people assemble role-related consumption stimuli to cultivate role-identities," (Kleine et al., 2006). It is reasonable to think that when a person is cultivating a role identity, he or she is moving towards their ideal self-image. The related consumption behaviors provide both symbolic and instrumental value to achieve the desired self-image. Identity theory provides understanding of motivation to consume for status within the group. Products and services possess personalities that status-seeking consumers desire to display in the attempt to achieve their ideal self-images, aiding in the process of symbolic selfcompletion (Grott and Johnson, 2013).

Consumers who are interested in status consumption tend to express themselves through purchase and use of brands (O'Cass and Frost, 2002). The association between a brand and its type of users often helps consumers to derive symbolic meaning from the brand (Muniz and O'Guinn, 2001). Status-seeking consumers, who prefer to purchase based on high price or uniqueness for the purpose of differentiating themselves within their social group and display wealth (Amaldoss and Jain, 2005), are more likely to visit retail outlets that they find congruent with this superior self-image.

The following hypothesis is therefore derived:

H9: Status consumption positively influences self-congruity. 


\section{Methodology}

\section{Data collection and sample}

To demonstrate the proposed model, we chose to use Generation Y consumers in Malaysia due to their growing patronage of branded coffee cafés. Generation Y refers to a group of people who were born between 1986 and 2005 (Markert, 2004). Generation Y members are shown to be socially and brand conscious (Thwaites et al., 2012; Eastman and Liu, 2012). Correspondingly, generation Y consumers are inclined to overspend for branded products (Phau, 2014). Although it was commonly believed that wealthier Generation Y consumers tend be involved in luxury brand consumption (Piacentini and Mailer, 2004), some scholars have asserted that social stratum is irrelevant (Eastman et al., 1999). In other words, less wealthy consumers are equally involved in luxury brand consumption. This may due to financial support received from indulgent parents (Butcher et al., 2016). Generation Y remains an interesting cohort to be considered in the context of revisiting branded coffee cafés as they tend to look for elements beyond price and quality when making purchase decisions.

This study used a purposive sampling method in selecting questionnaire respondents. Subjects from Gen-Y were approached in a university campus in Malaysia, and questionnaires were administered face-to-face. The minimum sample size necessary, calculated using G*Power software (Faul et al., 2007) was 107. We collected 320 questionnaires but 10 were discarded due to incomplete answers, resulting in 310 useable responses. The sample includes 105 males and 205 females who ranged in age from 21 to 31. A total of $38.7 \%$ of respondents have income below RM 1000 (236.77 USD) per 
month, followed by $34.5 \%$ with income ranging from RM1001 to RM3000 per month (237.01USD to 710.31USD), and 26.8\% ranging from RM3001 to RM5000 per month (710.55USD to $1183.85 \mathrm{USD})$.

\section{Measures}

For avoidance of similarity, a scale with four items was adapted from Tian et al. (2001). The status consumption scale with four items was adapted from Eastman et al. (1999). Four items sourced from Sirgy et al. (1997) were used to measure self-congruity. Perceived value was measured using PERVAL-Short scale by Walsh et al. (2014), with three items for each of the four dimensions; functional, monetary, social, and emotional value. Measurement of intention to revisit was adapted from Kivela et al. (1999). A 5point Likert scale was used for exogenous constructs and a 7-point Likert scale for the endogenous constructs. The variation helps as a remedy for common method bias (Mackenzie and Podsakoff, 2012). In addition, assurance of anonymity and an effort to highlight of the importance of honest responding were emphasized to increase the quality of the survey responses (Chang et al., 2010).

\section{Results}

Our first steps were to ensure the quality of data. To assess the presence of common method bias in this study, the Harmen Single Factor test was conducted (Podsakoff et al., 2003). The results revealed that the largest variance explained by the first factor was $29.28 \%$ of the total variance, below threshold value of $40 \%$ (Babin et al., 2016). All variables did not form a single factor and a single factor did not explain the 
majority of variance between items. Furthermore, a marker variable was used as an exogenous variable predicting every endogenous construct within the model (Rönkkö and Ylitalo, 2011). Comparing the baseline model and marker variable model, the decision for hypothesis testing remains unchanged. There are only small changes in $\mathrm{R}^{2}$ across the two models (See appendix). Therefore, it is concluded that common method bias is not a serious concern in this study.

To analyze the proposed research model, Partial Least Square Structural Equation Modeling (PLS-SEM) was applied using SmartPLS version 3.2.6 (Ringle et al., 2015). PLS-SEM was used because the objective of this study is to maximize explanation of variance (prediction of constructs) (Hair et al., 2017). The two-stage analytical procedure by Anderson and Gerbing (1988) was applied by examining the measurement model first followed by the structural model.

\section{Measurement Model}

Convergent and discriminant validity were examined via a measurement model. Average variance extracted (AVE), composite reliability (CR), and indicator loadings were examined for convergent validity. As depicted in Table 1, all constructs exhibited AVE greater than 0.5 , composite reliability above 0.7 , and indicator loadings above 0.6 . An item, SC 4 was deleted due to low loadings. FUNC 3 was not deleted because Hair et al. (2017) suggested retaining indicators with loadings between 0.4 and 0.7 if CR and AVE were already satisfied. As illustrated in Figure 1, perceived value was modeled as a second-order construct. Hence, this study followed the repeated indicator approach 
method suggested in PLS literature (Becker et al., 2012). In brief, convergent validity was established (Hair et al., 2017).

\section{Insert Table 1 about here}

Next, the discriminant validity of the measured constructs was examined using Heterotrait-Monotrait ratio of correlations (HTMT) approach (Henseler et al., 2015). As shown in Table 2, all HTMT values were below required threshold value of 0.85 (Kline, 2011). Furthermore, the HTMT inferential was assessed using bootstrapping. The result of HTMT inference exhibited that the confidence interval does not straddle 1 on any constructs. This further confirmed the discriminant validity of the measures (Henseler $e t$ al., 2015).

Insert Table 2 about here

\section{Structural Model}

Collinearity issues were examined before hypothesis testing to look for the presence of highly correlated constructs. The result revealed that the highest VIF value was 2.093, well below the suggested threshold of 3.3 (Diamantopoulus and Sigouw, 2006). A bootstrapping sample of 5000 was used to test the proposed hypotheses. As shown in Table 3, self-congruity was positively related to revisit intention, overall perceived value, and its dimensions. Overall perceived value was positively related to revisit intention. In particular, three perceived value dimensions, namely functional, emotional, and social value were positively related to revisit intention. However, monetary value was not significantly related to revisit intention. In addition, avoidance of 
similarity and status consumption were positively related to self-congruity. In brief, all the proposed direct relationships from $\mathrm{H} 1$ to $\mathrm{H} 9$ were supported by the data, except that H5 was partially supported. $47.0 \%$ of the total variance is explained by the model. If we substitute overall perceived value with value dimensions, the $\mathrm{R}^{2}$ value rises slightly to 49.4\%. We further considered the effect sizes using Cohen's $f^{2}$ (Cohen, 1988), which the values of $0.35,0.15,0.02$ indicate large, medium, and small effect sizes respectively. Of importance, perceived value had the largest effect size on revisit intention. Looking into details, emotional value carries the highest effect. Status consumption had medium effect on self-congruity.

Insert Table 3 about here

Subsequently, we assessed the mediating effect of perceived value in the relationship between self-congruity and revisit intention. As shown in Table 4, all the mediating effects of overall perceived value and its dimensions were found, except monetary value. Thus, H6 was supported and H7 was partially supported. In view of the significant direct and indirect effects of self-congruity on revisit intention, complementary partial mediations were evidenced (Zhao et al., 2010).

Insert Table 4 about here 


\section{Post-hoc test}

We further conducted a post-hoc test to explore whether there are direct and indirect effects of avoidance of similarity and status consumption on perceived value. Results showed that the direct effects of avoidance of similarity on perceived value and its dimensions were not significant. Status consumption was positively related to overall perceived value $(\beta=0.122, \mathrm{p}<0.05)$. However, in a specific manner, status consumption only significantly influenced social value $(\beta=0.182, \mathrm{p}<0.05)$. The result revealed that self-congruity completely mediated the avoidance of similarity--perceived value link ( $\beta=$ $0.09, \mathrm{p}<0.05)$ and partially mediated the status consumption--perceived value link $(\beta=0.216, \mathrm{p}<0.05)($ Zhao et al., 2010).

\section{Discussion and implications}

The purpose of this research was to build upon the model used by Roy and Rabbanee (2015) and extend understanding of the antecedents and consequences of selfcongruity. Within the context of Generation Y consumers' patronage of branded coffee cafés in Southeast Asia, where such consumption is a luxury, we tested a model with avoidance of similarity and status consumption as antecedents of self-congruity and perceived value and revisit intention as outcomes. The two outcomes are expansions of the earlier model.

The first hypothesis predicted a direct path between self-congruity and revisit intention for branded coffee cafés. The direct path value is lower than that of the indirect path beginning with self-congruity through perceived value to revisit intention. This suggests 
partial mediation. Still, the more congruent our subject felt branded coffee cafés were with their self-concept, the more likely they intend to visit the cafés again. This finding builds upon those in Roy and Rabbanee (2015) who showed hedonic use and selfperception as the outcomes of self-congruity but who did not test for purchase or revisit intention. Including revisit intention in the model allows for more recommendations to marketing practitioners.

In our second hypothesis, we proposed that the subjects' self-congruity with branded coffee cafés would be positively related to their overall perceived value obtained from those cafés. $\mathrm{H} 2$ was also supported with a large effects size. The result is in line with findings of Shamah et al. (2017) and Ha and Im (2012). There is little research that tests the direct relationship between self-congruity and perceived value but the hypothesized connection is logically to be expected. Only in a pathological vision of the self would we expect to see a consumer expressing that a product or service is a lot like how they would ideally see themself, and perceive low value in that object at the same time. Conversely, it is just as perverse to imagine a consumer viewing a product or service as not congruent with the self and still hold high value for the offering. Our model tests and makes explicit that among our subjects, where there is higher self-congruity; there is also a more favorable perception of value.

The third hypothesis which indicated the effect of self-congruity on perceived value dimensions was partially supported. The result is complementary to H2. Previous studies have not probed into the links between self-congruity and first-order value dimensions. 
The result demonstrates that self-congruity leads to greater perceived value gained in terms of functional, monetary, emotional, and social values. Hence, the biasing effect of self-congruity on product utilitarian aspects is not only replicated but extended further to psychological feeling. Of importance, the effect is particularly greater in social value, in line with the context of this study where young consumers are able to express and achieve their ideal selves through the consumption of branded coffee cafés.

Our findings support $\mathrm{H} 4$ which states that overall perceived value impacts revisit intention on branded coffee cafés in Malaysia. The path between perceived value and revisit intention had a large effect size $\left(f^{2}=0.429\right)$. This is a common finding in the marketing literature and recent examples demonstrating this relationship are available (Salehzadeh and Pool 2017; Naseem et al. 2015). In fact, the study of value is a dominant stream in marketing research today. Even in the case of luxury products, consumers rationalize the purchase of products that strain their budget by ascribing value to such products. As shown in $\mathrm{H} 5$, we ran a subsequent test where the four facets of value were modeled as leading directly to revisit intention to take a deeper look at the most important aspect of value in determining revisit intention. We found that functional, emotional and social value had significant paths to revisit intention and that monetary value did not. So, the consumers who valued branded coffee cafés did so for reasons other than the economic value. They rationalize spending more for better coffees and services, a more comfortable and enjoyable environment, the social setting and how visiting the branded coffee cafés made them feel. Hence, young consumers in Malaysia are willing to pay for 
high end food and beverage to gain the other value dimensions, where monetary value is a less important concern.

Findings also supported the propositions in $\mathrm{H} 6$ and $\mathrm{H} 7$ which predicted that overall perceived value and its dimensions act as mediators between self-congruity and revisit intention. The mediation in self-congruity--value-intention link is not commonly studied in consumer behavior literature. Therefore, we see it as one of the major contributions of this paper. Value is a powerful determinant of consumer behavior. It is not surprising that it partially mediates the impact of self-congruity on purchase intention and it is worth knowing that value pre-dominates self-congruity even for the purchase of trendy, relatively expensive products. This finding together with that for $\mathrm{H} 1$ implies that marketers might place more emphasis on the role of perceived value, especially functional, emotional, and social values in developing revisit/purchase intention as its impact is stronger and mediates that of self-congruity.

Hypothesis 8 was supported in its prediction that avoidance of similarity is positively related to self-congruity. This replicated the findings of Roy and Rabbanee (2015) and Arbore et al. (2014), and explains that people desire to see themselves as special and use branded goods and services to "wear" or display that individuality to others. Patronage of expensive food outlets when income is low works to demonstrate being current and exhibit wealth. Walking down the street with a Starbucks cup in hand sets young consumers apart in a developing world. 
Hypothesis 9 predicted that higher status consumption is related to higher self-congruity with branded coffee cafés. Hypothesis 9 was supported and again replicates the findings of Roy and Rabbanee (2015). While there is not a lot of previous research that links these two constructs, there is good logical basis for this finding. When an individual consumer is more motivated to display status, the more he or she finds upscale branded coffee cafés to be congruent with self-image. It is surprising to know that branded coffee cafés are attractive symbols for Generation Y in Malaysia. In more developed countries with higher income, Starbucks, for example, might be more of convenience and less of a status symbol. We demonstrate that within this sample, patronage at branded coffee cafés fits with status concerned consumers' images of themselves. A reaction that we might more typically associate with designer clothing or high-end automobiles was found to extend to branded coffee within our Malaysian sample.

The post-hoc test results indicate that consumers with high status consumption evaluate branded coffee cafés more favorably. This is credited to the reason that branded coffee cafés provide more meaning to this group of consumers, not only contributing to the image of the ideal self but also helping them to convey their desired image to others. The data shows that the relationships between avoidance of similarity, status consumption, and perceived value are chiefly explained by self-congruity. Consumers who crave social distinctiveness and social status perceive greater value because branded coffee cafés offer a coherent source of self, and at the same time, means to present the self.

\section{Managerial Implications}


One application of our findings is that branding a simple thing, such as coffee, and building that brand can produce a reaction that we might more typically associate with designer clothing or high-end automobiles. At least this is the case within our Malaysian sample. The fact that retail patronage is an act of public consumption makes it suited for branding as a status or luxury product. This might not be easy to achieve but it is possible as demonstrated by Starbucks and others.

The finding of higher self-congruity with branded coffee cafés leading to more perceived value in patronizing those cafés, holds value for managers. It shows that using market communications to convey self-congruency and how that translates into the perception of value. Coffee café managers might want to use opinion leaders who can reflect an embodiment of the image younger consumers are trying to match. In order to reach their segment, use of models or spokespersons who dress in similar ways and participate in activities that are congruent with the segment should be beneficial.

Perceived value as a mediator between self-congruency and revisit intention has implications for marketing strategy as well. This finding demonstrates that companies need to communicate the social, emotional, and functional value found in their offerings. Showing the café as meeting these needs should be useful. Too much emphasis on the kind of people who patronize a service or display use of a product may smack of pandering that should be avoided as the message needs subtlety. Understanding that the non-economic aspects of value are the main driving force for revisit intention offers a coherent messaging strategy for marketers. 


\section{Conclusion}

The data we collected supported the majority of hypotheses proposed. This study has extended the work of Rabbanee and Roy (2015) by adding a four-factor measure of perceived value and behavioral intention to the model. We have expanded the understanding of how self-congruity functions and demonstrated the mediating power of value in relation to behavior in the form of intention to revisit. Future research should test the model with more sorts of products and in different settings. Our sample, though appropriate to the product category, is limited by geography, age and culture. It would be interesting to test it in other countries and do a comparison using a broader group of consumers. The antecedent of consuming for status is a powerful and consistent motivator across cultures (Eastman et al., 1997). It would be interesting to see if the other relationships hold in different cultures.

\section{References}

Agriculture and Agri-Food Canada (2014), "Market access secretariat: Global analysis report: Food service profile: Malaysia", available at: http://www5.agr.gc.ca/resources/prod/Internet-Internet/MISB-DGSIM/ATSSEA/PDF/6510-eng.pdf.

Arbore, A., Soscia, I., \& Bagozzi, R.P. (2014), "The role of signaling identity in the adoption of personal technologies", Journal of the Association for Information Systems, Vol. 15 No. 2, pp. 86-110.

Aguirre-Rodriguez, A., Bosnjak, M. and Sirgy, M.J. (2012), "Moderators of the selfcongruity effect on consumer decision-making: A meta-analysis", Journal of Business Research, Vol. 65 No. 8, pp. 1179-1188.

Ahuvia, Aaron, C. and Wong, N. (1995), "Materialism: Origins and implications for personal well-Bbing," in European Advances in Consumer Research (Ed), Association for Consumer Research, Flemming Hansen, Copenhagen, pp.172-178. 
Amaldoss, W. and Jain, S. (2005), "Pricing of conspicuous goods: A competitive analysis of social effects", Journal of Marketing Research, Vol. 42 No. 1, pp. 30-42.

Anderson, J.C. and Gerbing, D.W. (1988), "Structural equation modeling in practice: A review and recommended two-step approach", Psychological Bulletin, Vol. 103 No. 3, pp. 411-423.

Arbore, A., Soscia, I. and Bagozzi, R.P. (2014), "The role of signaling identity in the adoption of personal technologies", Journal of the Association for Information Systems, Vol. 15 No. 2, pp. 86-110.

Babin, B.J., Darden, W.R. and Griffin, M. (1994), "Work and/or fun: Measuring hedonic and utilitarian shopping value", Journal of Consumer Research, Vol. 20, No.4, pp. 644656.

Babin, B.J., Griffin, M. and Hair, J.F. (2016), "Heresies and sacred cows in scholarly marketing publication”, Journal of Business Research, Vol. 68 No. 8, pp. 3133-3138.

Becker, J.M., Klein, K. and Wetzels, M. (2012), "Hierarchical latent variable models in PLS-SEM: guidelines for using reflective-formative type models", Long Range Planning, Vol. 45 No. 5, pp. 359-394.

Berjaya Food Berhad (2016), "Berjaya Food Berhad Annual Report. Kuala Lumpur", available at:

http://www.malaysiastock.biz/GetReport.aspx?file=AR/2016/8/18/5196\%20-\%20171859 1702105.pdf\&name=BFood\%20Annual\%20Report $\% 202016 \% 20-\% 201 . \mathrm{pdf}$

Butcher, L., Phau, I. and Teah, M. (2016), "Brand prominence in luxury consumption: Will emotional value adjudicate our longing for status?", Journal of Brand Management, Vol. 23 No. 6, pp.1-15.

Chang, S.J., Van Witteloostuijn, A. and Eden, L. (2010), "From the editors: Common method variance in international business research", Journal of International Business Studies, Vol. 41 No. 2, pp. 178-184.

Clark, M. (1997), "Modelling the impact of customer-employee relationships on customer retention rates in a major UK retail bank", Management Decision, Vol. 35 No.4, pp. 293-301.

Cohen, J. (1988), Statistical power analysis for the behavioral sciences (2nd ed.), Lawrence Erlbaum Associates, Hillsdale, NJ.

Eastman, J. K., Fredenberger, B., Campbell, D. and Calvert, S. (1997), “The relationship between status consumption and materialism: a cross-cultural comparison of Chinese, 
Mexican, and American student", Journal of Marketing Theory and Practice, Vol. 5 No. 1, pp. 52-66.

Eastman, J.K. and Liu, J. (2012), "The impact of generational cohorts on status consumption: an exploratory look at generational cohort and demographics on status consumption", Journal of Consumer Marketing, Vol. 29 No. 2, pp. 93-102.

Eastman, J.K., Goldsmith, R.E. and Flynn, L.R. (1999), "Status consumption in consumer behavior: Scale development and validation", Journal of Marketing Theory and Practice, Vol. 7 No. 3, pp. 41-52.

Eggert, A. and Ulaga, W. (2002), "Customer perceived value: A substitute for satisfaction in business markets?", The Journal of Business \& Industrial Marketing, Vol.17 No. 2/3, pp. 107-118.

Faul, F., Erdfelder, E., Lang, A.-G. and Buchner, A. (2007), "G*Power 3: A flexible statistical power analysis program for the social, behavioral, and biomedical sciences", Behavior Research Methods, Vol. 39, pp. 175-191.

Fornell, C. and Wernerfelt, B. (1987), "Defensive marketing strategy by customer complaint management: A theoretical analysis", Journal of Marketing Research, Vol. 24 No.4, pp. 337-346.

Fournier, S. (1998), "Consumers and their brands: Developing relationship theory in consumer research”, Journal of Consumer Research, Vol. 24 No. 4, pp. 343-353.

Goi, C.L. (2013), "Factors influencing customers to visit coffee chains", World Review of Business Research, Vol. 3 No. 4, pp. 172-183.

Goi, M.T., Kalidas, V. and Zeeshan, M. (2014), "Comparison of stimulus-organismresponse framework between international and local retailer", Procedia-Social and Behavioral Sciences, Vol. 130, pp. 461-468.

Graeff, T.R. (1996), "Using promotional messages to manage the effects of brand and self-image on brand evaluations", Journal of Consumer Marketing, Vol. 13 No. 3, pp. 418.

Grotts, A.S. and Johnson, T.W. (2013), "Millennial consumers' status consumption of handbags", Journal of Fashion Marketing and Management: An International Journal, Vol. 17 No. 3, pp. 280-293.

Ha, S. and Im, H. (2012), "Identifying the role of self-congruence on shopping behavior in the context of US shopping malls", Clothing and Textiles Research Journal, Vol. 30 No. 2, pp. 87-101. 
Hair, J.F., Hult, G.T.M., Ringle, C.M. and Sarstedt, M. (2017), A Primer on Partial Least Squares Structural Equation Modeling (PLS-SEM) (2nd ed.), Sage, Thousand Oakes, CA.

He, H. and Mukherjee, A. (2007), "I am, ergo I shop: Does store image congruity explain shopping behaviour of Chinese consumers?", Journal of Marketing Management, Vol. 23 No. 5/6, pp. 443-460.

Heaney, J-G., Goldsmith, R.E., and Wan Jusoh, W.J. (2005), "Status consumption among Malaysian consumers: Exploring its relationships with materialism and Attention-toSocial-Comparison-Information," Journal of International Consumer Marketing, Vol. 17 No. 4, 83-98.

Henseler, J., Ringle, C.M. and Sarstedt, M. (2015), “A new criterion for assessing discriminant validity in variance-based structural equation modeling", Journal of the Academy of Marketing Science, Vol. 43 No. 1, pp. 115-135.

Holbrook, M.B. (1994), "The nature of customer's value: An axiology of service in consumption experience", in Rust, R.T. and Oliver, R.L. (Eds.), Service Quality: New Directions in Theory and Practice, Sage Publications Thousand Oaks, CA, pp. 21-71.

Hosany, S. and Martin, D. (2012), "Self-image congruence in consumer behaviour", Journal of Business Research, Vol. 65 No. 5, pp. 685-691.

Hwang, J. and Kandampully, J. (2015), "Embracing CSR in pro-social relationship marketing program: Understanding driving forces of positive customer responses", Journal of Services Marketing, Vol. 29 No.5, pp.344-353.

Kang, J., Tang, L. and Lee, J.Y. (2015), "Self-congruity and functional congruity in brand loyalty", Journal of Hospitality \& Tourism Research, Vol. 39 No. 1, pp. 105-131.

Kim, H.R., Lee, M. and Ulgado, F.M. (2005), "Brand personality, self-congruity and the consumer brand relationship", in Ha, Y.-U. and Yi, Y. (Eds.), AP - Asia Pacific Advances in Consumer Research, Association for Consumer Research, Duluth, MN, pp. 111-117.

Kim, M., \& Thapa, B. (2017), "The influence of self-congruity, perceived value, and satisfaction on destination loyalty: a case study of the Korean DMZ", Journal of Heritage Tourism, pp. 1-13.

Kivela, J., Inbakaran, R. and Reece, J. (1999), "Consumer research in the restaurant environment, part 1: A conceptual model of dining satisfaction and return patronage", International Journal of Contemporary Hospitality Management, Vol. 11 No. 5, pp. 205222. 
Kleine, S.S., Kleine, R.E. and Laverie, D.A. (2006), "Exploring how role-identity development stage moderates person-possession relations", in Belk, R.W. (Ed.), Research in Consumer Behavior, Emerald Group Publishing Limited, Bingley, United Kingdom, pp.127-163

Kline, R.B. (2011). Principles and Practice of Structural Equation Modeling. Guildford Publications, New York, NY.

Kressmann, F., Sirgy, M. J., Herrmann, A., Huber, F., Huber, S., \& Lee, D. J. (2006), "Direct and indirect effects of self-image congruence on brand loyalty", Journal of Business Research, Vol. 59 No. 9, pp. 955-964.

Lin, J.N.J. and Yun, C.T. (2016), "Young adults' motivation to patronize independent specialist coffee shops in Malaysia", in: Abdullah, M., Yahya, W., Ramli, N., Mohamed, S. and Ahmad, B. (Eds), Regional Conference on Science, Technology and Social Sciences (RCSTSS 2014), Springer, Singapore.

$\mathrm{Lu}, \mathrm{J}$. and $\mathrm{Xu}, \mathrm{Y}$. (2015), “Chinese young consumers' brand loyalty toward sportswear products: A perspective of self-congruity", Journal of Product and Brand Management, Vol. 24 No. 4, pp. 365-376.

MacInnis, D.J. and Folkes, V.S. (2017), "Humanizing brands: When brands seem to be like me, part of me, and in a relationship with me", Journal of Consumer Psychology, Vol. 27 No. 3, pp. 355-374.

MacKenzie, S.B. and Podsakoff, P.M. (2012), "Common method bias in marketing: Causes, mechanisms, and procedural remedies", Journal of Retailing, Vol. 88 No. 4, pp.542-555.

Maclnnis, D. and Jaworski, B. (1989), "Information processing from advertisements: Toward an integrative framework”, Journal of Marketing, Vol. 53 No. 4, pp. 1-23.

Markert, J. (2004), "Demographics of age: Generational and cohort confusion”, Journal of Current Issues and Research in Advertising, Vol. 26 No. 2, pp. 11-25.

McCracken, G. (1986), "Culture and consumption: A theoretical account of the structure and movement of cultural meaning of consumer goods", Journal of Consumer Research, Vol. 13 No. 1, pp. 71-84.

Mencarelli, R. and Riviere, A. (2015), "Perceived value in B2B and B2C: A comparative approach and cross-fertilization”, Marketing Theory, Vol. 15 No. 2, pp. 201-220.

Muniz, A.M. and O'guinn, T.C. (2001), "Brand community", Journal of Consumer Research, Vol. 27 No. 4, pp. 412-432. 
Nadiri, H. and Gunay, G.N. (2013), "An empirical study to diagnose the outcomes of customers' experiences in trendy coffee shops”, Journal of Business Economics and Management, Vol.14 No. 1, pp. 22-53

Naseem, N, Verma, S. and Yaprak, A. (2015), "Global brand attitude, perceived value, consumer affinity, and purchase intentions: A multidimensional view of consumer behavior and global brands", in Barbara Stöttinger, B., Schlegelmilch, B.B. and Zou, S. (Eds.), International Marketing in the Fast Changing World (Advances in International Marketing), Emerald Group Publishing Limited, Bingley, United Kingdom, pp. 255-288.

O'cass, A. and Frost, H. (2002), "Status brands: Examining the effects of non-productrelated brand associations on status and conspicuous consumption", Journal of Product \& Brand Management, Vol. 11 No. 2, pp. 67-88.

Parasuraman, A. and Grewal, D. (2000), "The impact of technology on the quality-valueloyalty chain: A research agenda", Journal of the Academy of Marketing Science, Vol. 28 No. 1, pp. 168-174.

Phau, I. (2014), “'Domestic-made' or 'foreign-made' luxury brands?”, in Choi, T.M. (Ed.), Fashion Branding and Consumer Behaviors, Springer, New York, NY, pp. 77-100.

Piacentini, M. and Mailer, G. (2004), "Symbolic consumption in teenagers' clothing choices", Journal of Consumer Behaviour, Vol. 3 No. 3, pp. 251-262.

Podsakoff, P.M., MacKenzie, S.B., Lee, J.Y. and Podsakoff, N.P. (2003), “Common method biases in behavioral research: A critical review of the literature and recommended remedies", Journal of Applied Psychology, Vol. 88 No. 5, pp. 879-903.

Ringle C.M., Wende, S. and Becker, J.M. (2015). "SmartPLS 3”, available at: www.smartpls.com

Rönkkö, M. and Ylitalo, J. (2011), "PLS marker variable approach to diagnosing and controlling for method variance", Thirty Second International Conference on Information System (ICIS), Shanghai, Proceedings Paper 8. Available at: https://aisel.aisnet.org/icis2011/proceedings/researchmethods/8

Roy, R. and Rabbanee, F. K. (2015), “Antecedents and consequences of self-congruity”, European Journal of Marketing, Vol. 49 No. 3/4, pp. 444-466.

Salehzadeh, R. and Pool, J.K. (2017), "Brand attitude and perceived value and purchase intention toward global luxury brands", Journal of International Consumer Marketing, Vol. 29 No. 2, pp. 74-82.

Shamah, R.A., Mason, M.C., Moretti, A. and Raggiotto, F. (2017), "Investigating the antecedents of African fast food customers' loyalty: A self-congruity perspective”, 
Journal of Business Research, In Press, available at:

http://www.sciencedirect.com/science/article/pii/S0148296317301662

Sheth, J.N., Newman, B.I. and Gross, B. L. (1991), "Why we buy what we buy: A theory of consumption values", Journal of Business Research, Vol. 22 No.2, pp. 159-170.

Simonson, I. and Nowlis, S.M. (2000), "The role of explanations and need for uniqueness in consumer decision making: Unconventional choices based on reasons", Journal of Consumer Research, Vol. 27 No. 1, pp. 49-68.

Sirgy, M.J. (1982), "Self-concept in consumer behaviour: A critical review", Journal of Consumer Research, Vol. 9 No. 3, pp. 287-300.

Sirgy, M.J. (1985), "Using self-congruity and ideal congruity to predict purchase motivation", Journal of Business Research, Vol. 13 No. 3, pp. 195-206.

Sirgy, M.J., Grewal, D. and Mangleburg, T.F. (2000), "Retail environment, selfcongruity, and retail patronage: An integrative model and a research agenda", Journal of Business Research, Vol. 49 No. 2, pp. 127-138.

Sirgy, M.J., Grewal, D., Mangleburg, T.F., Park, J., Chon, K., Claiborne, C.B., Johar, J.S. and Berkman, H. (1997), "Assessing the predictive validity of two methods of measuring self-image congruence", Journal of the Academy of Marketing Science, Vol. 25 No. 3, pp. 229-241.

Sirgy, M.J., Johar, J.S., Samli, A.C. and Claiborne, C.B. (1991), "Self-congruity versus functional congruity: Predictors of consumer behavior", Journal of the Academy of Marketing Science, Vol.19 No. 4, pp. 363-375.

Susanty, A. and Kenny, E. (2015), "The relationship between brand equity, customer satisfaction, and brand loyalty on coffee shop: Study of Excelso and Starbucks. ASEAN Marketing Journal, Vol. 7 No. 1, 14-27.

Sweeney, J.C. and Soutar, G.N. (2001), "Consumer perceived value: The development of a multiple item scale", Journal of Retailing, Vol. 77 No. 2, 203-220.

Thwaites, D., Lowe, B., Monkhouse, L.L. and Barnes, B.R. (2012), "The impact of negative publicity on celebrity ad endorsements", Psychology \& Marketing, Vol. 29 No. 9, pp. 663-673.

Tian, K.T., Bearden, W.O. and Hunter, G.L. (2001), "Consumers need for uniqueness: Scale development and validation", Journal of Consumer Research, Vol. 28 No. 1, pp. 50-66. 
Ting, H. and Thurasamy, R. (2016), "What matters to infrequent customers: a pragmatic approach to understanding perceived value and intention to revisit trendy coffee café", SpringerPlus, Vol.5 No.1, 651.

Veblen, T. (1899), The Theory of the Leisure Class, Macmillan, New York, NY.

Walsh, G., Shiu,E. and Hassan, L.M. (2014), "Replicating, validating, and reducing the length of the consumer perceived value scale", Journal of Business Research, Vol. 67 No. 3, pp. 260-267.

Zeithaml, V.A. (1988), "Consumer perceptions of price, quality, and value: A means-end model and synthesis of evidence", Journal of Marketing, Vol. 52 No. 3, pp. 2-22.

Zhao, X., Lynch Jr, J.G., \& Chen, Q. (2010), "Reconsidering Baron and Kenny: Myths and truths about mediation analysis. Journal of Consumer Research, Vol. 37 No. 2, pp. 197-206. 